\title{
Occupational Pensions: Securing the Pension Promise*
}

\author{
Roy Goode $\dagger$
}

I received the invitation to deliver this lecture with decidedly mixed feelings. I was, of course, flattered to be asked to contribute to this long-established series so generously sponsored by the Royal Bank of Scotland. But having embarked in 1992 on an enquiry in a field about which I knew absolutely nothing, and spent a fascinating 15 months with extraordinarily knowledgeable colleagues before handing in our Report, I have been trying desperately ever since to escape from everything to do with occupational pensions. This has proved a good deal more difficult than I had thought!

As I am sure you are all aware, today is the second anniversary of the establishment of the Pension Law Review Committee. I will not ask whether you regard this as a happy event or a cause for grief. Suffice it to say that our two-volume Report, which contains 218 recommendations and weighs some 118 ounces, was delivered to the Secretary of State on 30 September 1992, seven consulatation papers were issued by the Department of Social Security [D.S.S.] in the ensuing months, the most recent publication of the House of Commons Select Committee on Social Security (on whose recommendation we were set up) is given over entirely to a Report on our Report, and a government White Paper is imminent. What will be in it I do not know. My hope is that it will substantially adopt the package of proposals we put forward, with whatever fine tuning may be necessary. But we shall see.

\section{GENERAL CONSIDERATIONS}

My talk tonight is devoted to a central plank of our Report, security for the Pension promise. By the pension promise I mean the totality of retirement and related benefits promised to a worker by his employer. The provision of an occupational pension scheme is a voluntary act on the part of an employer. It is for the employer to decide whether to provide a pension, what should be the conditions of eligibility and level of contributions and benefits, and what powers of amendment and wind-up the employer wishes to reserve. We have considered that in general the employer should continue

\footnotetext{
* This is the revised text of the Royal Bank of Scotland Lecture, delivered at the University of Oxford on 8th June 1994.

† Norton Rose Professor of English Law in the University of Oxford, Fellow of St. John's College, Oxford.
} 
to enjoy these freedoms. There are, of course, existing legislative restrictions on this freedom of trust, such as the preservation of accrued rights after two years' service and the indexation of deferred pensions, and we have recommended a few more. But the employer cannot be expected to leave its future financial commitments to be determined by third parties.

What we have said, however, and very firmly, is that whatever benefits are promised should be properly secured. There are many different types of event that can jeopardise the solvency of a pension fund, but they fall broadly into three groups.

First, there is deliberate underfunding of the scheme. The employer is not obliged to set up a scheme or to fund it at any particular level. There are many unfunded schemes, primarily top-up schemes to provide pensions above the earnings cap. A measure of funding is required as a condition of tax exemption or to secure contractingout status, but it is a relatively small proportion of the cost of benefits under a normal final salary scheme.

Secondly, there are the normal forecasting risks: the falsification of economic projections, such as salary growth and the relationship between earnings and prices, and of demographic projections, such as mortality rates and rates of withdrawal through ill-health, early retirement or redundancy. These matters are the domain of the actuary, and they are pregnant with uncertainty. Indeed, the only actuarial assumption that is invariably right is that all other actuarial assumptions are invariably wrong! The law faces a delicate problem in this area. On the one hand, it has to respond to the need for flexibility in order to accommodate the myriad situations that can arise. On the other, the range of permitted assumptions must not be so broad as to undermine the entire credibility of the actuarial exercise. This is a problem we urged the actuarial profession to address, and it is doing so with vigour.

Thirdly, there are what may be termed pathological risks, of the kind so vividly demonstrated by the Maxwell affair: excessive self-investment, failure to pay contributions when due, and the theft of pension fund assets or their diversion to improper purposes which wrongfully benefit third parties at the expense of the pension fund.

My primary concern is with the security of pensions payable under final salary schemes. Members of money purchase schemes may suffer from misappropriation or negligent investment of assets but the risk of ordinary underfunding does not arise in money purchase schemes, which are by their nature fully funded, since the benefits are measured directly by the value of contributions to the fund.

There are various ways in which the pension promise may be secured. One is by insuring the benefits, which in this country is very common for the smaller schemes. But wholly insured schemes, which are almost always money purchase, rarely attract the problems I am addressing. Another is termination (or insolvency) insurance, of the kind exemplified in America under ERISA through the Pension Benefit Guarantee Corporation [P.B.G.C.] This form of security no doubt has its place. But as the American experience shows it is no substitute for adequate funding - the P.B.G.C. is currently facing a deficit estimated at between 12 billion and 20 billion dollars 
and one expert has estimated that the total amount of underfunding in the United States amounts to 51 billion dollars - and raises a serious moral hazard issue in that the premiums levied on pension funds result in well-funded schemes subsidising those that are poorly run.

The third route, adopted in this country for the vast majority of schemes, is funding, and that is the route we have followed. Our basic approach has been that schemes should be required to be fully funded at all times. Of course, this would not solve all the problems. Premature wind-up of a scheme causes problems for scheme members even if there is a sufficiency of assets to cover accrued liabilities, for benefits cease to accrue and the final salary benchmark will be that at the time of wind-up, not the final salary the scheme member would have received if the scheme had continued and he or she had remained in it until normal retirement age. But we did not feel anything could be done about this. Just as loss of employment is an inherent, though regrettable, risk of everyday life, so also is the possibility of a scheme wind-up. What one can do is to seek to ensure that the scheme assets are sufficient to cover entitlements accrued up to the date of wind-up.

Under the present law the employer is liable for any deficiency in assets on the wind-up of a scheme. Accordingly so long as the employer remains solvent scheme members are already adequately protected against the risk of scheme insolvency. This is subject to the important qualification that the employer's statutory duty on wind-up of a scheme is not to ensure that the pensions are able to be paid when due but to pay the cash equivalent of the accrued rights. If the actuarial calculation of the cash equivalent turns out to be accurate it will be sufficient to cover the accrued liabilities. But the cash equivalent provisions undoubtedly change the nature of the pension promise, from final salary to money purchase. There is no guarantee that the cash equivalent will in fact be sufficient to purchase or otherwise provide for salary-related pensions. For practical reasons I shall indicate a little later, it has not proved possible to overcome this particular problem.

Subject to this qualification, there is at the end of the day only one risk for scheme members, the insolvency of the employer and its consequent inability to make good a scheme deficit in accordance with the statutory requirements. Unfortunately there is no way of securing the employer's continued solvency. No company, however, strong it may appear, is wholly immune from the risk of insolvency. This means that the present regime, by which statutory liability is imposed on the employer only at the point when the scheme or the employer is wound up, is inherently inadequate, for the protective measure comes too late. What is required is full funding continuously throughout the scheme and steps to ensure that this is maintained.

A full funding requirement is, of course, concerned with any case of asset deficiency, from whatever cause, and the first half of my talk will examine the implications of our proposals for funding and the responses these have received. But the risk of loss of assets through pathological events calls for additional protective measures. These will form the second half of this lecture. 


\section{THE CONCEPT OF FULL FUNDING}

Within the limits of what is practicable our strongly held view was that the pension promise should be fully funded at all times. To promise scheme members more than the scheme can actually deliver is a dangerous snare for members rely, and are entitled to rely, on the integrity of the pension promise. There are those who say that to provide adequate security by a full funding requirement could lead to a reduction in guaranteed benefits and a corresponding increase in discretionary benefits. There is no evidence to suggest that this would happen. But in any event, without full funding, what is the guarantee worth anyway? Surely it is better that members should be able to feel the pension promise means what it says than that they should be lulled into a false sence of security by the promise of higher guaranteed benefits for which there is no adequate underpinning.

There has in fact been widespread support for our general approach to a funding requirement. The central debate has focused on what full funding entails and how it can be achieved without imposing on schemes burdens disproportionate to the benefits.

There are two facets of scheme solvency. One is the cash flow test: the ability of an ongoing scheme to meet its liabilities as they fall due. This is primarily an actuarial matter, but its implications for investment strategy in the case of very mature schemes are only now coming to be recognised. The liquidity of the assets must be responsive to the projected outflows. The greater proportion of pensioners to active members, the greater the degree of liquidity required. I make no apology for stating what may seem to you to be obvious, because I believe it is only recently that those accustomed to seeing the benefits of an 80 per cent investment in equities have started to become uncomfortably aware of the cash flow implications of an ageing membership. It was at one time thought that the ratio of pensioners to active members cease to increase at the point where inflows matched outflows, so that in the graphic words of Joanne Livingstone, "pension schemes might stay forever mature, but preserved from old age as middle-aged 'Peter Pans'." Unhappily the trend is one of a relentless move to an ageing membership profile. We should do well to consider steps to reverse this trend by taking up the ideas so eloquently advocated by the Carnegie Report on Life, Work and Livelihood in the Third Age. I believe strongly that we should seek to increase rather than reduce the labour force and consider a return to the days when there was no concept of automatic retirement at a given age. But all this is beyond the scope of my subject tonight.

The second facet of scheme solvency is the balance sheet test: the ability of a scheme to meet its liabilities on winding up. A final salary scheme which is comfortably solvent on an ongoing basis, where no contributions are coming in, payments have to be made only when benefits fall due, and assets and liabilities are valued on the footing of long-term actuarial, assumptions, might well be unable to ensure the discharge of its liabilities if it were to be immediately wound up.

Why should this be so? The reason is that when a final salary scheme is wound 
up two things happen. First, it becomes necessary to provide for liabilities to existing and future pensioners, and this can be done only by the purchase of annuities and deferred annuities from life offices or (if they were available) long-term fixed-interest or index-linked securities.

Accordingly the efect of winding up is to convert a revenue liability spread over a long period into an immediate capital, or buy-out, liability. It is this acceleration of future liabilities that lies at the heart of the problem. The securities market has never provided sufficiently long-term securities for pension funds and there is no longer an insurance market for large-scale annuities and deferred annuities at an acceptable price or, indeed, at all. Secondly, assets to meet the capital liability have to be immediately available. This means that long-term actuarial values, which can be computed without reference to short-term fluctuations in the market, are replaced by market values, and if the time of winding up coincides with a severe fall in the market the solvency of the scheme may be impaired. How, then, is this problem to be dealt with?

One approach, advocated by some, is to abandon the notion of funding for discontinuance liabilities altogether and simply require schemes to be solvent on an ongoing basis. Most schemes are intended to continue as ongoing schemes, so why require them to be funded as if they were to be wound up? Though this approach seems to have found favour with the Select Committee, it is not easy to perceive the logic of a solvency standard which works only on the hypothesis that the very situation for which it is designed will never actually happen!

Another solution, the establishment of a Central Discontinuance Fund [C.D.F.], is the brainchild of Watsons and the Government Agency. It is a form of insurance against scheme insolvency but with two significant differences. In the first place, the scheme would not pay premiums as it goes. It is only at the point when the scheme folds that the C.D.F. would enter the scene, taking over scheme liabilities for a lumpsum premium represented by the accrued value of the liabilities plus a margin to reduce the risk of the C.D.F. becoming insolvent. Secondly, the C.D.F. would operate as if it were itself an ongoing defined benefit scheme and would adopt the equitybased investment strategy characteristic of ordinary schemes. This would reduce premiums compared, for example, with the cost of buying annuities and deferred annuities, and enable the accrued liabilities of the failed scheme to be valued on an ongoing basis. The C.D.F. is an imaginative way of tackling the serious problem of funding for discontinuance, to which I shall return later, but is not without its risks. The Government Actuary was, indeed, good enough to tabulate for us what he engagingly described as the probability of ruin! For the reasons set out in our Report we concluded that there were too many imponderables for it to be endorsed without a good deal of further work, so I shall say nothing further about it tonight.

The solution advocated by my Committee was to require the purchase of annuities for pensioners - in recognition of the fact that the liabilities to them were immediate - but to provide deferred pensioners (including the members who were active members prior to wind-up) with a transfer value equal to the cash equivalent of their accrued 
rights as increased by limited price indexation, but excluding discretionary benefits. The provision of cash equivalents admittedly changes the nature of the benefit from final salary to money purchase, but this is inescapable and is no different from what we have now. Schemes that in fact fund for discretionary benefits and salary increases above RPI (Retail Prices Index) (as many do) would have a cushion. Moreover, for schemes not predominantly consisting of pensioners the conventional gilts yield assumption could properly be modified to take account of the service profile of members and allow some movement towards equities, and thus the investment strategy of an ongoing fund. This would bring down the transfer price.

These were the broad lines of approach adopted by the Committee. Our restricted timetable did not allow us to get into detail, and we recognised that some fine tuning might be necessary. The actuaries then got to work and it soon became clear that whilst they were in broad agreement with our approach, both as to the need for full funding and as to the impracticability of requiring full buy-out with annuity policies, there was a division of opinion among them as to the likely effect of adopting our proposals as they stood. Some considered that this could force schemes either to create mismatching reserves or to shift their investment policy away from equities, with a consequent reduction in long-term returns. Others felt that our proposed minimum solvency standard would not create any difficulty, and that such problems as might arise were there already, typically because of a mismatch of assets and liabilities in very mature schemes.

The conclusions of the actuarial profession as reflected in their responses to the D.S.S.'s consultation paper are that the Committee's approach should work quite satisfactorily if modified in the following respects:

(a) Instead of adopting a solvency measure based on buying from life offices annuities for pensioners, schemes should value liabilities to pensioners on the basis of the cost of buying best-matched investments. This was seen as a cheaper route, since it avoids the margins built in by insurance companies for expenses, profit and stringent solvency requirements.

(b) Cash equivalents should be computed in such a way as to reflect the profile of scheme membership, so that for an immature scheme it could be hypothesised that the yield would be largely equity-based, whilst for a very mature scheme a fixed-interest or interest-linked yield would be assumed, as now.

(c) For large schemes, which could find the cost of immediate buy-out of pensioners unacceptable, solvency should be determined on the basis that in the event of discontinuance the scheme would be run off as a closed (or perhaps more accurately a frozen) scheme, with an eventual buy-out of residual benefits. This would allow the use of scheme mortality rates instead of the rather lower rates that are normally adopted by life offices.

Following this response by the Institute of Actuaries and Faculty of Actuaries, the Department commissioned research from the Government Actuary's Department, 
which studied over 200 scheme valuation reports and concluded that 95 per cent would immediately meet the 100 per cent solvency requirements calculated on this modified basis. Similar results were obtained from a survey conducted by Bacon and Woodrow, which showed that most of the residual shortfall cases were executive schemes for the benefit of restricted groups of members.

There seems much to be said for this approach, which adopts a full funding standard, as we recommended, while hypothesising a lower cost for liabilities to pensioners and, in the case of large schemes, a run-off of other liabilities in a closed fund in lieu of an immediate buy-out.

Final judgement will have to be postponed until the government has crystallised its proposals. I would, however, utter one word of caution. If solvency of an ongoing scheme is to be measured on the basis of a run-off of liabilities in a closed fund, one has to be sure that this is the form of discontinuance that will actually be adopted, and that the scheme will not be immediately wound up, thus entirely vitiating the assumptions predicted on its being run off in a closed fund.

\section{THE TREATMENT OF DEFICIENCIES}

It is necessary to distinguish an ongoing scheme from one that has actually been discontinued. In the case of an ongoing scheme funding for discontinuance is on the basis of hypotheses which may never be put to the test or, if put to the test, may not be fully borne out. Once a scheme has discontinued the adequacy of its assets can then be established as fact. In addition, there is the question of priorities where there is a shortfall, a problem that does not confront an ongoing scheme.

\section{Deficiency in an ongoing fund}

Under our proposals, if a scheme at any time fell short of 100 per cent funding the trustees would have to submit a business plan showing how full funding would be restored within three years. But if the solvency level fell below 90 per cent steps would have to be taken to make good the shortfall within three months or such longer period as might be allowed by the Pensions Regulator, the supervisory authority we have proposed should be established.

There is widespread recognition of the need for a mechanism to enforce the solvency standard. The major argument concerns the treatment of schemes falling below the 90 per cent base level. In particular it is said that:

(a) the time allowed is too short;

(b) the employer may inject a substantial cash sum to cover what turns out to be a purely temporary dip in the market and will not be able to recover the over-funding;

(c) there are alternatives to a cash injection, such as the provision of a bank guarantee or other security. 
There is some force in these arguments. I remain of the view that a drop below the 90 per cent base level is potentially serious and must be dealt with much more quickly than a shortfall in the 90-100 per cent band, though it could be longer than three months. The problem of a cash injection that turns out to be excessive could be dealt with either by the provision of security or by allowing the employer, with the consent of the Regulator, to recover any payment that turned out to be excessive to requirements.

\section{Deficiency on a discontinuance}

The treatment of a deficiency where there is an actual discontinuance is in some ways simpler because it crystallises the position and to a considerable degree substitutes the known for the unknown. As now, the employer's liability to make good the deficiency then comes into operation. If the employer is insolvent it is then a question whether to apply the scheme priority rules or to substitute statutory rules of priority. It is, of course, a necessary concomitant of funding for discontinuance on the basis of cash equivalents that in the event of a deficiency the liability of the trustees becomes converted from the provision of a pension to the payment of the requisite transfer values. But it is not clear to me why this change should in itself affect the continued application of the priority rules laid down by the scheme.

\section{PATHOLOGICAL EVENTS}

I turn now to what I have described as pathological loss-causing events: non-payment of contributions, excessive self-investment, inappropriate withdrawal of "surplus", and misappropriation of assets. The first three of these can be dealt with quite shortly.

\section{Non-payment of contributions}

We had a significant volume of evidence to show that there was inadequate monitoring of payment of contributions, even in the case of insured schemes. We were told of one case in which no employer's or employees' contributions had been paid to the pension fund during the 29 months prior to the employer's insolvency! We have made various recommendations designed to deal with this, including a requirement for the trustees to agree a schedule of due dates of payment with the employer.

\section{Excessive self-investment}

At the time of the events arising in the Maxwell case there were no legal restrictions on the investment of pension funds in the sponsoring employer. Self-investment of this kind reverses the segregation effect of the trust by putting trust funds straight back into the employer's enterprise. Subsequently rules were introduced to limit selfinvestment to 5 per cent of a scheme's total resources. Unfortunately there are no sanctions for infringement. We have recommended a tightening of the rules in various respects, coupled with penalties for breach. 


\section{Inappropriate withdrawal of "surplus"}

There are several problems with so-called surpluses in an ongoing fund. First, any withdrawal of surplus funds by the employer reduces the security for benefit entitlements. Secondly, surplus is all too prone to evaporate, through a sustained fall in the market or an adverse change in the tax regime. Thirdly, the very existence of surplus may be open to question, since a relatively modest reduction in the assumed interest rate may substantially reduce the value of the assets. In the $L R T$ case, for example, it was calculated that a reduction of a half per cent in the assumed rate of future dividend growth would bring down the value of the fund by $£ 167$ milion and the past service surplus from $£ 460$ million to $£ 293$ million, a reduction of over 35 per cent. Accordingly we have recommended further restrictions, including a requirement of consent of the Pensions Regulator, who we have proposed should be appointed to oversee occupational pensions.

\section{Misappropriation of assets}

The really serious pathological event is the misappropriation of scheme assets by trustees or fund managers. The Maxwell case is in a class of its own for the sheer scale and variety of methods used to remove pension fund assets from the control of the trustees. Securities were sold by fund managers but the proceeds, instead of being paid to them, were transferred to Maxwell's private companies. Funds were improperly withdrawn and used in unsuccessful attempts to support the share price of Maxwell's public companies in order to maintain the value of shares pledged to banks as collateral. Pension fund securities were charged to banks as security for loans to the private companies. Stock was lent to the private companies without collateral and the stock loan was never repaid. In the Macmillan case, as Mr. Justice Millett held, the bizarre situation arose in which a merchant bank with whom shares had been deposited thought they were taking them as security for the loan of Treasury bills whereas the Chief Administrator of the group's pension schemes was under the impression that the bank was borrowing the shares, so that in respect of the same series of transactions each party thought that $i t$ was the lender and the other the borrower! All in all, the pension funds lost assets to the tune of some $\$ 450$ million, though quite a lot of that has since been recovered by litigation, arbitration or voluntary compromise.

How could all this happen? First, Maxwell himself possessed an overpowering personality in which utter ruthlessness was combined with an irresistible charm. Secondly, he had managed to put himself in control of all relevant parties. He was the chairman and controller of the two public companies whose pension funds were raided; he was the chairman of the trustee board; he was the chairman and controller of the in-house fund managers managing a substantial part of the funds; he was also chairman and controller of one of the principal external fund managers; and he controlled the private companies to which the assets were diverted. In fact, he was well placed to sign documents on behalf of every party to a transaction! Thirdly, for psychological reasons it is in many ways much easier to get away with a large 
swindle than a small one. Ask your bank manager for a loan of $£ 5$ and you'll be thrown out on your ear! Ask for $£ 5$ million and you'll be given it without question - unless, of course, you bank with The Royal Bank of Scotland!

The hardship and distress caused to the Maxwell pensioners led to strong criticisms of the present law, many of which, in my view, betrayed a misunderstanding both of the role of the law and the content of the legal rules. It was said, for example, that trust law, which is the foundation of pension schemes, was mediaeval and therefore inadequate, and that it had demonstrably failed in its purpose. That trust law is mediaeval is undoubtedly true. That it is therefore inadequate seems to me a fairly massive non sequitur. It is worth remembering that at the end of the First World War we hanged Roger Casement for treason under the Treason Act 1351, which was certainly mediaeval but undoubtedly effective! Moreover, trust law cannot prevent breaches of trust any more than criminal law can prevent crime. At best it is a deterrent.

There were, however, other more cogent proposals put to us which I will briefly describe. One was that pension fund securities should be designated with the name of the pension fund or its trustees. Designation is in fact quite widely used, but would create significant problems in managing pooled funds. Moreover, the protection given by designation is legally much more limited than its proponents suppose. The primary utility of designation is in facilitating an audit trail and in preventing the same batch of security certificates being produced over and over again to different auditors. But it is also commonly supposed that if the name of the pension fund is shown on securities certificates third parties buying the securities will be fixed with notice of the title of the pension fund and will therefore be subordinate to the rights of scheme members. This supposition is based on a misconception of the law. Specifically it fails to take account of the distinction between a passive, or bare, trust, under which the function of the trustee is purely to hold the legal title without any powers of management, and an active trust, under which the trustees are given full powers to manage and deal in the trust assets. This distinction between the bare trust and the active trust, which our textbooks tend to treat as of little importance, is in fact fundamental to our problem. The reason is that a bare trustee cannot pass a good title to a third party who takes with notice of the trust, whereas in the case of a trustee who has management powers the third party who acquires the trust asset in good faith and for value takes free from the rights of the trust beneficiaries unless he knows not only that the assets are trust assets but that the disposition of them is in breach of trust. The same applies to disposals of securities by a fund manager acting whithin its actual or apparent authority.

The separate proposal that all pension fund securities should be held by an independent custodian meets much the same difficulty. Pension fund securities are not locked up in a box pending pay-out of benefits. They are constantly being sold and bought. For that purpose the trustees must either do it themselves or authorise someone else, such as fund managers, to do it for them. Either way, a custodian given an instruction to release securities for disposal has little choice but to obey the instruction if it is given by a person acting within the scope of his actual or apparent 
authority. A custodian cannot investigate the propriety of every transaction; the delay and expense would be substantial and, indeed, the delay alone could result in substantial loss. So while custodianship, like designation, is useful and widely used, its protective effect should not be exaggerated.

We concluded that neither designation nor independent custodianship, however desirable, should be made compulsory. We did, however, recommend a general tightening up of the monitoring of scheme assets by their auditors and actuaries. We also felt that whilst the moral hazard problem made it inappropriate to provide a compensation scheme against market risk, members of a pension scheme, whether final salary or money purchase, could not reasonably be expected to bear more than a small portion of the risk of loss through fraud, theft or other misappropriation. Hence our recommendation for a statutory compensation scheme, to be administered by a Pensions Compensation Board, providing for compensation of defrauded schemes up to 90 per cent of the misappropriated assets or 90 per cent of the scheme deficit, whichever was the lower. This would be financed by a post-event levy on all schemes, and there would be power to advance funds prior to, or even without, a finding of fraud in civil or criminal proceedings if the Board considered there was strong evidence that this had occurred.

I was asked by the House of Commons Select Committee on Social Security whether, if all our recommendations were to be placed, I could guarantee that there would never be a repetition of the Maxwell situation. I replied that if I were to answer yes to that question my credibility would be destroyed forever! The fact is that no amount of rule-making can prevent fraud. All one can do is to make it more difficult and more detectable at an earlier stage, so that losses can be kept down. I believe that the combination of our funding requirements, the supervisory and intervention powers of the Regulator, and the enhanced monitoring roles of the scheme auditor and the scheme actuary, will make substantial frauds less likely, and that where they do occur the compensation scheme will largely remove the risk of hardship and distress of the kind suffered by the Maxwell pensioners among others.

The measures we have proposed to provide safeguards against normal risks and pathological events do not represent a perfect situation, but they do in my view go a very long way to achieving one of our central objectives, security for the pension promise. 